The Turkish Online Journal of Design, Art and Communication - TOJDAC

ISSN: 2146-5193, September 2018 Special Edition, p.1024-1029

\title{
STRUCTURAL FEATURES OF THE LANGUAGE REPRESENTATION OF THE CONCEPT OF LONELINESS IN LEXICOGRAPHIC SOURCES
}

\author{
Olga N. PROKHOROVA \\ The National Research University "Belgorod State University", Russia \\ Igor V. CHEKULAI \\ The National Research University "Belgorod State University”, Russia \\ Svetlana A. FETTER \\ The National Research University "Belgorod State University”, Russia
}

\begin{abstract}
The most essential and accessible sources of our understanding of the content of a concept are dictionary definitions. The dictionary article contains the data of phonological, lexical, phraseological and grammatical levels of the language. Examples of the use of lexical items in the dictionaries give us an idea about their place in the cultural and axiological system of the speakers of a particular language. This article is devoted to the study of representation of LONELINESS concept in English lexicographic sources. We attempted to identify typical means of verbalization of the concept of LONELINESS in the English linguistic culture, to establish specific features of their structure and functioning, and to analyze and describe the constitutive characteristics of the concept of LONELINESS as a knowledge structure. The obtained results allow us to talk about the detailed contemplation of the concept under study by means of English lexicography, as well as to specify its axiological, conceptual and figurative components.
\end{abstract}

Keywords: concept, loneliness, definition, lexicography, seme.

\section{INTRODUCTION}

The results of the definition of the elements of consciousness, which a person carries out in the act of comprehension of the real and virtual world, are recorded in a form of some special text, which is a dictionary entry. It contains not only extensive linguistic but also cultural information. Examples of the use of lexical units allow us to comprehend the meaning of the concept in the cultural evaluative system of native speakers.

The composition of the dictionary article varies depending on the type of lexicographic source. There are linguistic and encyclopedic dictionaries. The measure of their information density varies: elements of the scientific world image are fixed in encyclopedic dictionaries; philological dictionaries record the details of the naive world image, that is, the knowledge that the average linguistic personality uses. The object of interpretation of philological dictionaries is not the reality itself, but a lexeme reflecting it. The genre of this interpretation is definition with systematical description of the most important characteristics (Komarova 1991).

The objective of this research is to analyze the peculiarities of representation of the LONELINESS concept in English language culture. We pursue the task to pick out the typical means of representation of LONELINESS, to determine the characteristic features of their structurization and functioning, to analyze the constitutional elements of the LONELINESS concept as a knowledge structure. The fact that we reveal the nuclear and peripheral characteristics of the studied concept accounts for the scientific novelty of the work.

The relevance of this research can be formulated as follows: the study of linguistic and cultural concepts in general and the conceptual structure of feelings in particular represent one of the promising areas of modern linguistics; LONELINESS is reflected in the semantics of units of language and communication of individuals, but the specifics of the representation of this concept in English language culture is still underresearched. 


\section{METHODS}

The objects of this research are the qualitative and quantitative characteristics of the methods of defining the language representatives of the LONELINESS concept. Dictionary definitions of lexemes objectifying the concept under study were used as the material for the research. The objectives of the study determined the choice of general scientific (hypothetical-inductive, deductive, introspective) and linguistic scientific methods: conceptual analysis, the method of component analysis on the basis of dictionary definitions, contextual analysis, interpretative analysis and a method of total sample.

\section{MAIN PART}

Nowadays lexicographers tend to describe the essence of the subject or phenomenon without limitation to its semantic features. It's arguable that modern philological dictionaries increasingly include elements of encyclopedic information.

Any compiler of a dictionary is facing difficulties. The quality of lexicographic representation of the concept largely depends on the sufficiency of study of a particular sphere. It is impossible to establish a clear semantic meaning if the phenomenon is underresearched and has very vague boundaries (Apresyan 1995, Podzolkova 2005, Prokhorova 2013).

There are two approaches to lexicographic representation of lexis - semantic and metaphoric.

Supporters of the semantic method are Y.D. Apresyan, A. Wierzbicka, L. N. Iordanskaya. Semasiologist Y.D. Apresyan adduces universal "patterns of interpretations". He considers that in the process of lexicographic representation of the concept, a translation is made from natural language into "semantic language", the units of which are "elementary meanings" (Apresyan 1995).

A. Wierzbicka developed the conception of "semantic primitives". It involves the creation of a short list of metalinguistic means with a narrow repertoire. This list includes: "substantives", "determinants and quantifiers", "mental predicates", "actions and events", "evaluation", "descriptors", "time and place", "metapredicates", "intensifiers", "taxonomy and partonomy".

But the prototype models of Y. D. Apresyan and A. Wierzbicka are quite uncommon in modern lexicography due to the fact that the semantic language is too formal and complicated. Native speakers give preference to definitions in natural language.

Adherents of the metaphorical model of definition are George Lakoff and mark Johnson. The use of metaphors as a meta-linguistic means of expression of the essence of the concept makes it possible to describe the most delicate, difficult for logical transmission facets of the expressed thought. Metaphor, representing a figurative comparison, appeals to sensual language experience. It helps to create proper associations for a deeper understanding of the received message (Johnson \& Lakoff 2003).

N. A. Krasavsky recommends the use of the following semantic categories in the interpretation of the representatives of emotions: generic category and species categories. The latter are divided into groups of semes: 1) "emotions and feelings", 2) "causation of emotions", 3) "conditions for the display of feelings", 4) "the consequences of experiencing emotions", 5) "object of emotion", 6) "the nature of the danger", 7) "the form of display of emotions", 8) "the duration of emotions", 9) "qualitative characteristics of emotions", 10) "awareness and control of emotion", 11) "the intensity of the experience of emotion", 12) "positive or negative symbolic meaning of emotions" (Krasavsky 2001).

First, we analyzed the lexicographical interpretation of LONELINESS in psychological dictionaries, representing a modern interpretation of this phenomenon in the English-speaking community. For example we adduce the entry "Loneliness" from "APA Dictionary of Clinical Psychology" (VandenBos 2013): «loneliness $n$. affective and cognitive discomfort or uneasiness from being or perceiving oneself to be alone or otherwise solitary. Psychological theory and research offer multiple perspectives: Social psychology emphasizes the emotional distress that results when inherent needs for intimacy and companionship are not met; cognitive psychology emphasizes the unpleasant and unsettling experience that results from a perceived discrepancy (i.e., deficiency in quantity or quality) between an individual's desired and actual social relationships. Psychologists from the existential or humanistic perspectives may see loneliness as an inevitable, painful aspect of the human condition 
that, nevertheless, may contribute to increased self-awareness and renewal». An entry similar in structure and contents we can find in "APA College dictionary of psychology» (APA College Dictionary of Psychology 2015).

The analysis of the foresaid definitions allows us to identify the following components of cognitive structure LONELINESS:

- $\quad$ generic seme (aspect of human condition; experience),

- $\quad$ causation (when inherent needs for intimacy and companionship are not met; from a perceived discrepancy between an individual's desired and actual social relationships),

- $\quad$ evaluation (distress; discomfort or uneasiness; unpleasant and unsettling experience; painful),

- the consequences of experiencing of LONELINESS (may contribute to increased selfawareness and renewal),

- $\quad$ awareness and control of LONELINESS (inevitable).

We can conclude that the phenomenon of LONELINESS in English-language psychological dictionaries is described quite clearly. Aforecited features make it possible to identify the state of LONELINESS quite easily.

To find out whether the phenomenon of LONELINESS is described in detail in linguistic dictionaries, we looked up its definitions in multiple dictionary sources: Loneliness, $n-1$ ) the condition of being lonely; 2) the state of being unfrequented by human beings; 3) love of retirement, disposition to solitude (Macmillan English Dictionary for Advanced Learners 2007); Loneliness, mass n. - 1) sadness because one has no friends or company; 2) the fact of being without companions; solitariness; 3) (of a place) the quality of being unfrequented and remote; isolation (Oxford Advanced Learner's Dictionary 2000); Loneliness, $n$. - the state of being lonely (CIDE Cambridge International Dictionary of English 1996); Loneliness, uncount n. - the unhappiness that is felt by someone because they do not have any friends or do not have anyone to talk to (Collins English Dictionary and Thesaurus 2015).

Since definitions often provided references to the lexeme "lonely", we studied the examples of lexicographical interpretation of this lexeme: lonely: adj. 1) unhappy because you are alone or have no friends; 2) long way from where people live; 3 ) done or happening while you are alone and feeling lonely (Macmillan English Dictionary for Advanced Learners 2007); 1) unhappy because you are not with other people; 2) a lonely place is a long way from where people live (CIDE Cambridge International Dictionary of English 1996).

We can conclude that lexical unit "loneliness" is used to refer to the mental state of the individual, physical isolation and locality.

Seme set of LONELINESS as mental condition includes the following components: a generic seme, a particular identifier of the word's belonging to a specific denotative sphere (condition, state); nominative seme (sadness, unhappiness); causation seme, identifies the causes of loneliness (having no friends; having no one to talk to); seme "negative evaluation" (unhappiness); seme "positive evaluation" (love, disposition).

In the definitions of LONELINESS as physical isolation lexicographers distinguish the following semes: generic seme (state, fact); causation seme (being unfrequented by human beings, being without companions).

In those cases, when "loneliness" acts as nomination for the secluded area, its seme set includes generic seme (quality), nominative seme (isolation), causation seme (being unfrequented and remote; situated long way from where people live).

A comparative analysis of the definition of the lexeme "loneliness" in different types of dictionaries provides the opportunity to evaluate the satisfactoriness of representation of the phenomenon under study in various fields of knowledge. It should be noted that quite clear definitions of this concept are given in philological dictionaries, but they do not indicate the consequences of experiencing LONELINESS and its controllability by the subject (indicated in psychological dictionaries). It also should be mentioned that none of the philosophical dictionaries and encyclopedias we have looked through (Bunin \& Yu 2004, Stanford Encyclopedia of Philosophy 2015, Blackburn 2008, Cambridge Dictionary of Philosophy 2008, Taliaferro \& Marty 2010) contains dictionary entries with the title "Loneliness". 
Many scientists state that the description of the concept is drawn from the description of syntagmatic and paradigmatic relations of lexemes nominating this concept (Apresyan 1995, Prokhorova 2013). We have considered the lexeme "lonellinesss", but it is only an element of the lexical and grammatical system of the language and is implemented as a member of a certain lexical paradigm; it's possible to realize it as the name of the semantic set, consisting of synonyms, correlated with the meaning of the word.

Taking into consideration the fact that complete synonyms for this kind of knowledge structures do not exist, we expected to identify some distinctive semantic features of different means of representing the concept of LONELINESS in English language culture. The objective of this part of our work was to designate the obligatory components of the concept under study, based on the results of the definitional analysis of linguistic units that are members of a synonymic row LONELINESS, as well as to identificate optional components, that allow to differentiate lexemes representing the concept under study.

We present the results of the analysis of the meanings of the nouns constituting the synonymic row of the word "loneliness": according to thesauri (Collins English Dictionary and Thesaurus 2015, Roget's Thesaurus of English Words and Phrases 2000, Oxford Thesaurus of English 2009), this row includes a number of synonymous nouns: jsolitude, dreariness, desertedness, solitariness, singleness, alienation, friendlessness, remoteness, withdrawal, isolation, forlornness, desolation, aloneness, lonesomeness, seclusion, confinement, privacy, quarantine, reclusiveness, retirement, separateness (21 units).

This number of synonyms indicates a detailed differentiation of extralinguistic continuum, during which the specific characteristics of LONELINESS acquire a separate nomination in the language, reflected in lexicographic sources. This fact testifies to the great importance of the phenomenon under study for the language personality in the English language culture.

The obligatory components and features included in the seme set of all synonyms are "state of isolation", "subject" and "stimulus". These semantic components form the conceptual core of the concept. Optional components: "goal", "consequences", "evaluation", "degree", "accountability" serve for the differentiation of synonyms (e.g., lexeme "solitude" includes the "positive evaluation" (pleasant, relaxing), while "desolation" includes only "negative evaluation" (great sadness, unattractive)).

The component analysis of dictionary definitions carried out in the course of this study allowed us to identify other lexical units of the English language, representing the concept of LONELINESS:

- nomination of secluded area: solitude, wilderness, desert, desolation, hinterland, backcountry, boondocks, borderland, bush country, frontier, outback, sticks, wasteland, woods;

- actions, leading to desolation of a subject of action: to isolate oneself, to retire, to seclude, to stand apart, to withdraw, leave behind, relinquish, abdicate, back out, bail out, bow out, chicken out, cop out, cut loose, desert, discard, discontinue, ditch, drop, drop out, duck, dump, dust, flake out, fly the coop, give up the ship, kiss goodbye, leave, leg it, let go, opt out, pull out, quit, run out on, screw, ship out, stop, storm out, surrender, take a powder, take a walk, throw over, vacate, walk out on, wash hands of, withdraw, yield;

- $\quad$ actions, leading to desolation of an object of action: to isolate, to insulate, to quarantine, to detach, to shut off, to desolate, to forsake, to abandon, to banish, dismiss, dispel, drive away, eject, eliminate, eradicate, evict, exclude, exile, get rid of, isolate, ostracize, oust, outlaw, relegate, remove, ban, deport, discard, discharge, dislodge, excommunicate, expatriate, proscribe, rusticate, sequester, transport, cast out, expulse, extradict, shake off, shut out;

- nominations of a lonely person: individualist, loner, hermit, anchorite, bachelor, spinster, lonely heart, recluse, eremite, misanthrope, solitaire, stylite, pillarist, solitarian, introvert, lone wolf, outsider, me and my shadow, me myself and I;

- features of a person experiencing loneliness: lonely, solitary, lone, lonesome, single, unsociable, secluded, anomic, isolated, alone, all alone, friendless, companionless, without friends/ companions, with no one to turn to, outcast, forsaken, abandoned, rejected, unloved, unwanted, unpopular, sad, unhappy, forlorn, despondent.

Formulated by an elite linguistic personality of lexicographer, illustrative component of dictionary entries is of the greatest interest for researcher in the field of language culture studies. It represents the examples of the most typical use of certain lexemes in the appropriate contexts. These examples, in

Submit Date: 11.07.2018, Acceptance Date: 24.08.2018, DOI NO: 10.7456/1080SSE/141

Research Article - This article was checked by Turnitin

Copyright (C) The Turkish Online Journal of Design, Art and Communication 
our opinion, are most relevant culturally. The analysis of those examples helped us to get an accurate idea of the specifics of the language understanding of the phenomenon under study in a particular language community.

We conducted linguistic cultural study of the examples given in the definition of the lexemes representing concepts in dictionary entries with the use of methods of interpretation, introspection and component analysis of dictionary definitions. We were able to classify illustrations of the use of lexemes of interest in several semantic groups. For this study, we used the most authoritative lexicographical sources.

As a result, of the analysis of lexicographic examples illustrating the functioning of the means of verbalization of the concept LONELINESS in speech, we identified the following semantic components of the concept:

1. $\quad$ generic seme - "the state of isolation."

2. Subject-initiator (acts voluntarily, controls the situation): On his wife's death, he shut his son off from his friends in order to keep him for himself.

3. Subject- experiencer (obeys uncontrolled circumstances or violence): His mother abandoned him when he was five days old because she didn't have enough money for the two of them.

4. Causation (can be people (animate causators), their actions directed towards the subject (which in this case can only act as an experiencer, but not initiator), sensual images, internal needs and interests of the subject, physical and mental characteristics of the subject, etc. Causationy can also be expressed implicitly: Victims feel isolated and unable to talk about their experiences. All the patients known to have been in contact with the virus were immediately isolated.

5. $\quad$ Purpose: Important witnesses are isolated from the media for their own safety.

6. Consequences: Any move to isolate Brian would be very damaging to his health.

7. Positivelnegative evaluation: At the age of 83 she finally retired from public life.

8. Controllability: When people got angry, she withdrew into her shell.

9. Degree: Abed with gout he felt utterly desolate.

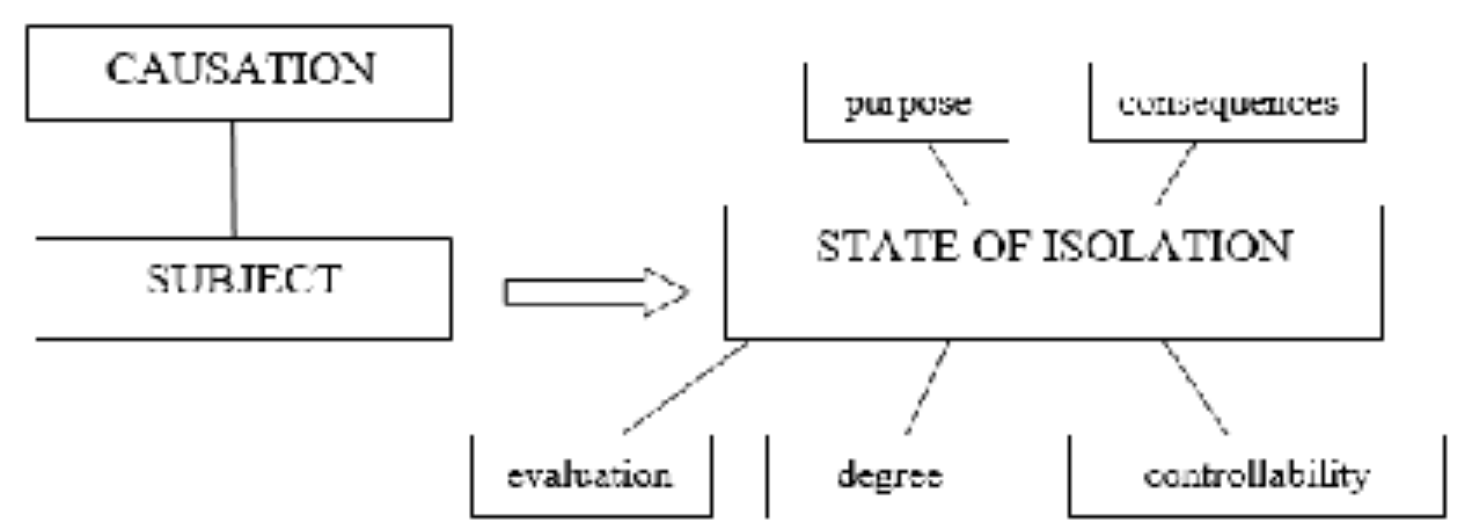

Figure 1. Structure of LONELINESS (according to the results of analysis of dictionary entries)

\section{CONCLUSION}

As a result of the analysis of functioning of linguistic units in the texts of lexicographic examples we discovered semantic features clarifying the meaning of the concept which hadn't been identified during the analysis of dictionary entries.

To sum up the aforecited research, we conclude that the English concept of LONELINESS is rather detailed objectivated in the lexicographical sources, which may indicate its high importance for English language consciousness. The result of the research consists in selection of the means of represenation of LONELINESS in English dictionary entries, specification of the features of their structure and functioning in the English language, identification through the analysis of the constitutive elements of the concept of LONELINESS and structural arrangement of its nuclear and peripheral components, verification of its figurative, conceptual and evaluation components. 
The Turkish Online Journal of Design, Art and Communication - TOJDAC

ISSN: 2146-5193, September 2018 Special Edition, p.1024-1029

\section{REFERENCES}

"APA College Dictionary of Psychology". (2015). Washington, DC: American Psychological Association.

Apresyan, Y.D. (1995). "Izbrannie trudy. Vol. II. Integralnoe opisanie yazika i sistemnaya lexicographia" ["Selected works. Vol. II. Integral description of the language and systemic lexicography"]. Moscow: Shkola "Yaziky russkoi kultury".

Blackburn, S. (2008). Oxford Dictionary of Philosophy. Oxford: Oxford University Press.

Bunin, N. \& Yu, J. (2004). "Blackwell Dictionary of Western Philosophy". Oxford: Blackwell Publishing.

"Cambridge Dictionary of Philosophy". (2008). Cambridge: Cambridge University Press.

"CIDE: Cambridge International Dictionary of English". (1996). Cambridge: Cambridge University

Press.

"Collins English Dictionary and Thesaurus". (2015). Harper Collins Publishers Ltd.

Johnson, M. \& Lakoff, G. (2003). "Metaphors We Live by". Chicago: University of Chicago Press.

Komarova, Z.I. (1991). "Semanticheskaya structura specialnogo slova i ego lexicographicheskoe opisanie" ["Semantic structure of a special word and its lexicographical description"]. Sverdlovsk.

Krasavsky, N.A. (2001). "Emotsionalnie concepty v nemetskoy $i$ russkoy lingvokulturah: Monographia" ["Emotional concepts in German and Russian linguocultures: Monograph"]. Volgograd: Peremena.

"Macmillan English Dictionary for Advanced Learners". (2007). Macmillan Education.

"Oxford Advanced Learner's Dictionary". (2000). Oxford: Oxford University Press.

"Oxford Thesaurus of English". (2009). Oxford: Oxford University Press.

Podzolkova, N.V. (2005). "Concept «odinochestvo» v nemetskoy i russkoy lingvokulturah: Dissertatsia kandidata philologicheskih nauk" ["The concept "loneliness" in German and Russian lingvocultures: Diss. of cand. of philol. sci."]. Volgograd.

Prokhorova, O.N. (2013). "Natsionalniy component semantiky abstraktnyh lexicheskih $i$ phraseologicheskih edinits" ["The national component of the semantics of abstract lexical and phraseological units"]. Yazik I kultura, 2, 68-81.

"Roget's Thesaurus of English Words and Phrases". (2000). New York: Penguin Books.

"Stanford Encyclopedia of Philosophy". (2015). Center for the Study of Language and Information (CSLI), Stanford University. Retrieved August 16, 2018, from: http://plato.stanford.edu.

Taliaferro, C. \& Marty, E.J. (2010). "Dictionary of Philosophy of Religion”. New York: Continuum.

VandenBos, G.R. (2013). "APA Dictionary of Clinical Psychology". Washington DC: American Psychological Association. 